\title{
Interpretación de las anomalías esqueléticas y su contribución a la investigación forense.
}

Contributions of skeletal abnormality interpretation to forensic investigation.

Douglas H. Ubelaker

Cuad Med Forense 2003; 33:35-42

El objetivo principal de la antropología forense es aportar información que contribuya a la determinación de: I/ La identidad del cadáver/es, y 2/ Qué le/s ocurrió. Al intentar tal estudio, el antropólogo forense debe primero evaluar qué características van probablemente a ser más útiles, y emplear todos los procedimientos científicos disponibles. Aunque pueden realizarse numerosas observaciones, las alteraciones patológicas y otras características anormales van a ser de especial utilidad.

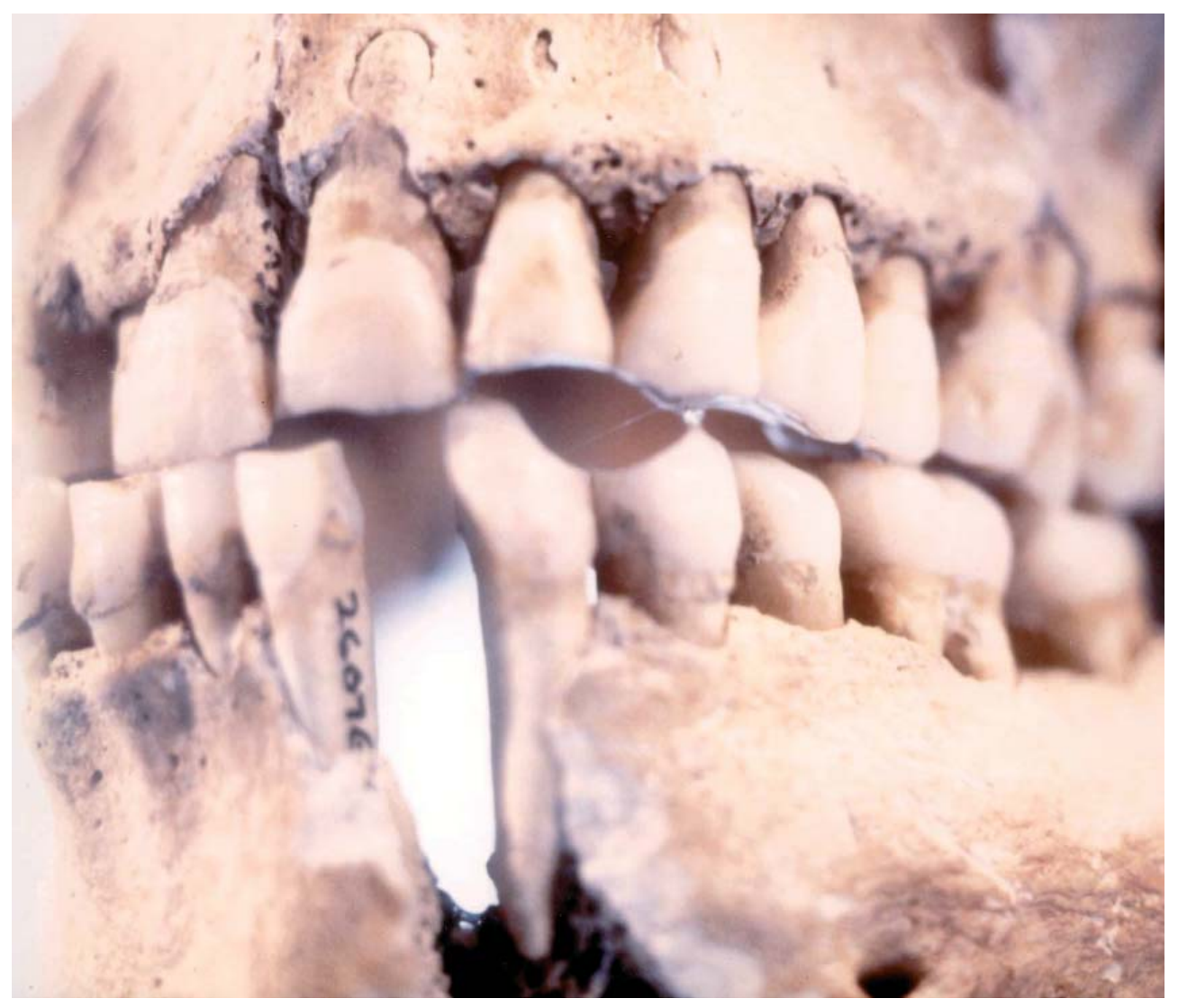

Figura 1.- Dentadura que muestra desgaste por pipa. Período colonial de Maryland (Estados Unidos). 


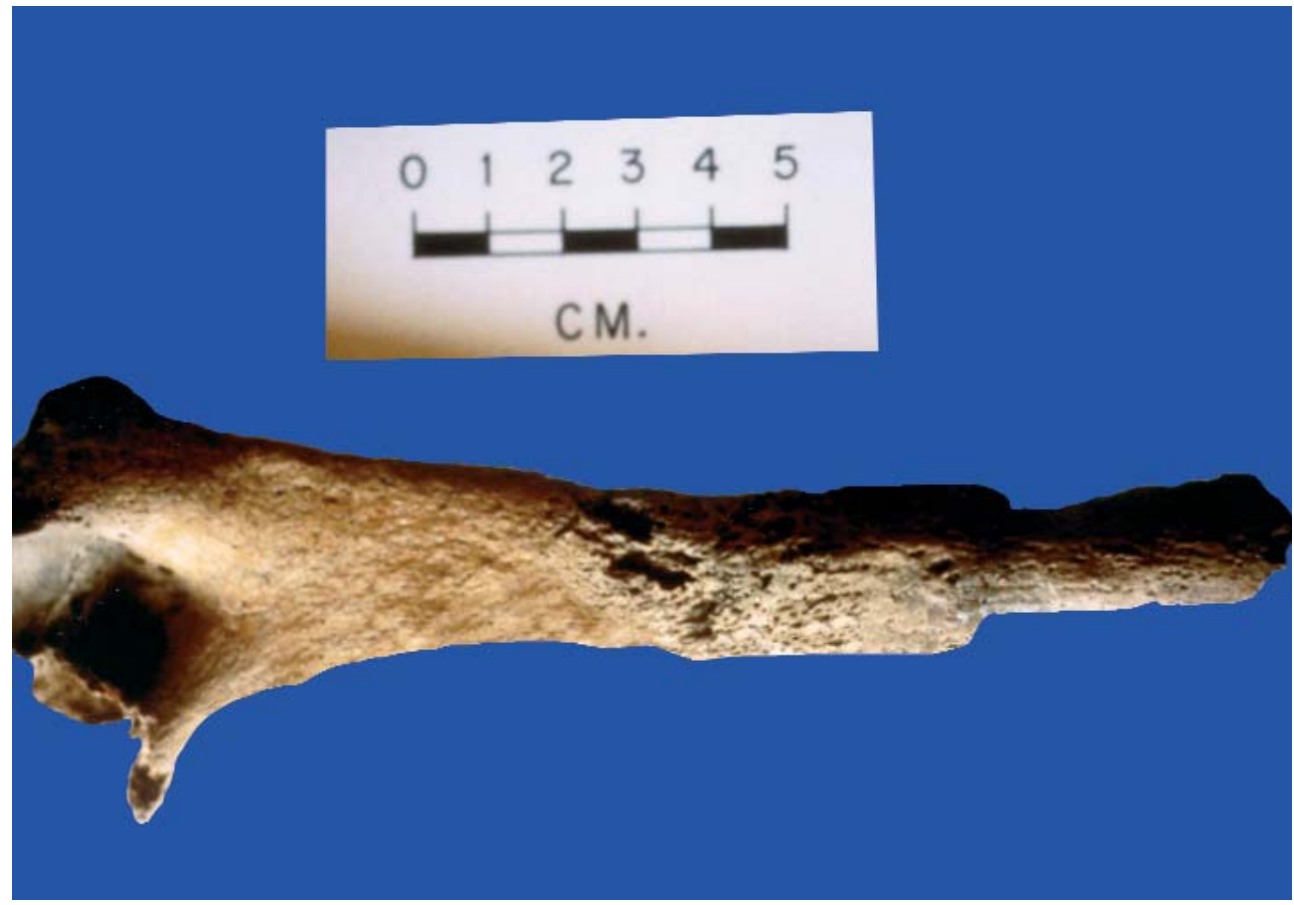

Figura 2.- Ejemplo de osteomielitis. Excavación arqueológica en Ecuador.

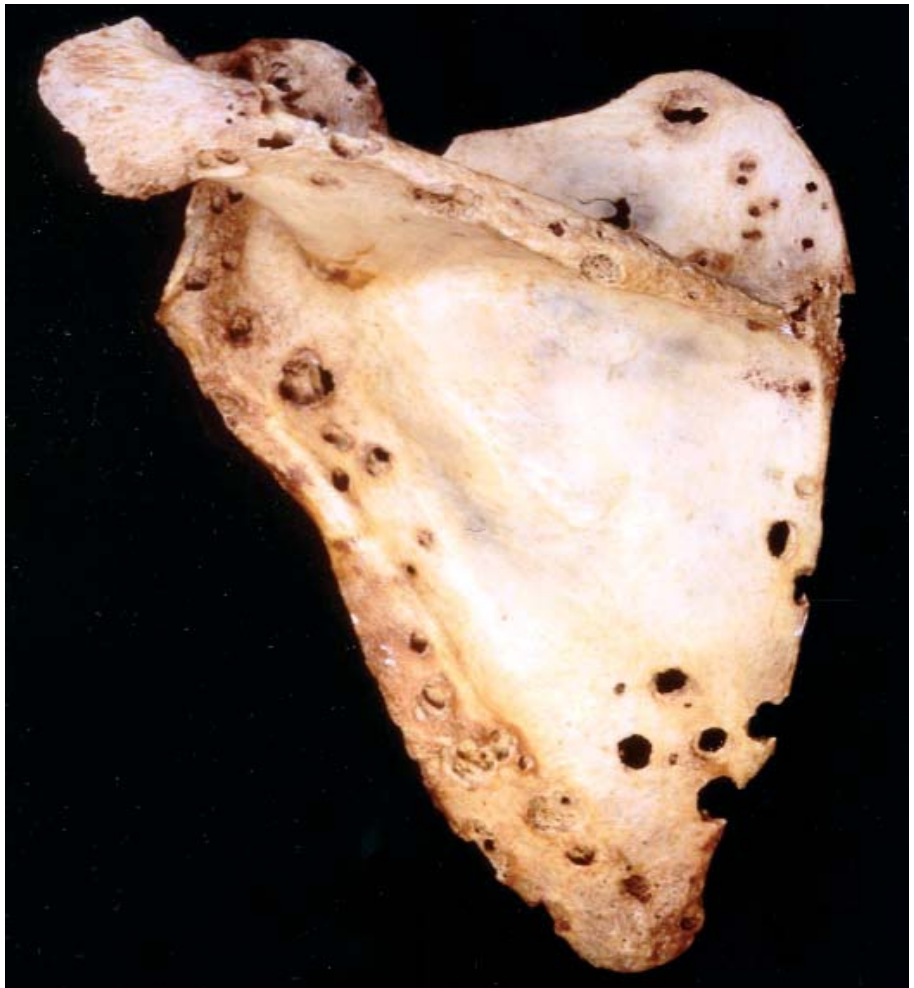

Figura 3.- Escápula de un individuo diagnosticado de Mieloma Múltiple. Nótese la mínima reacción ósea asociada a esta patología. 


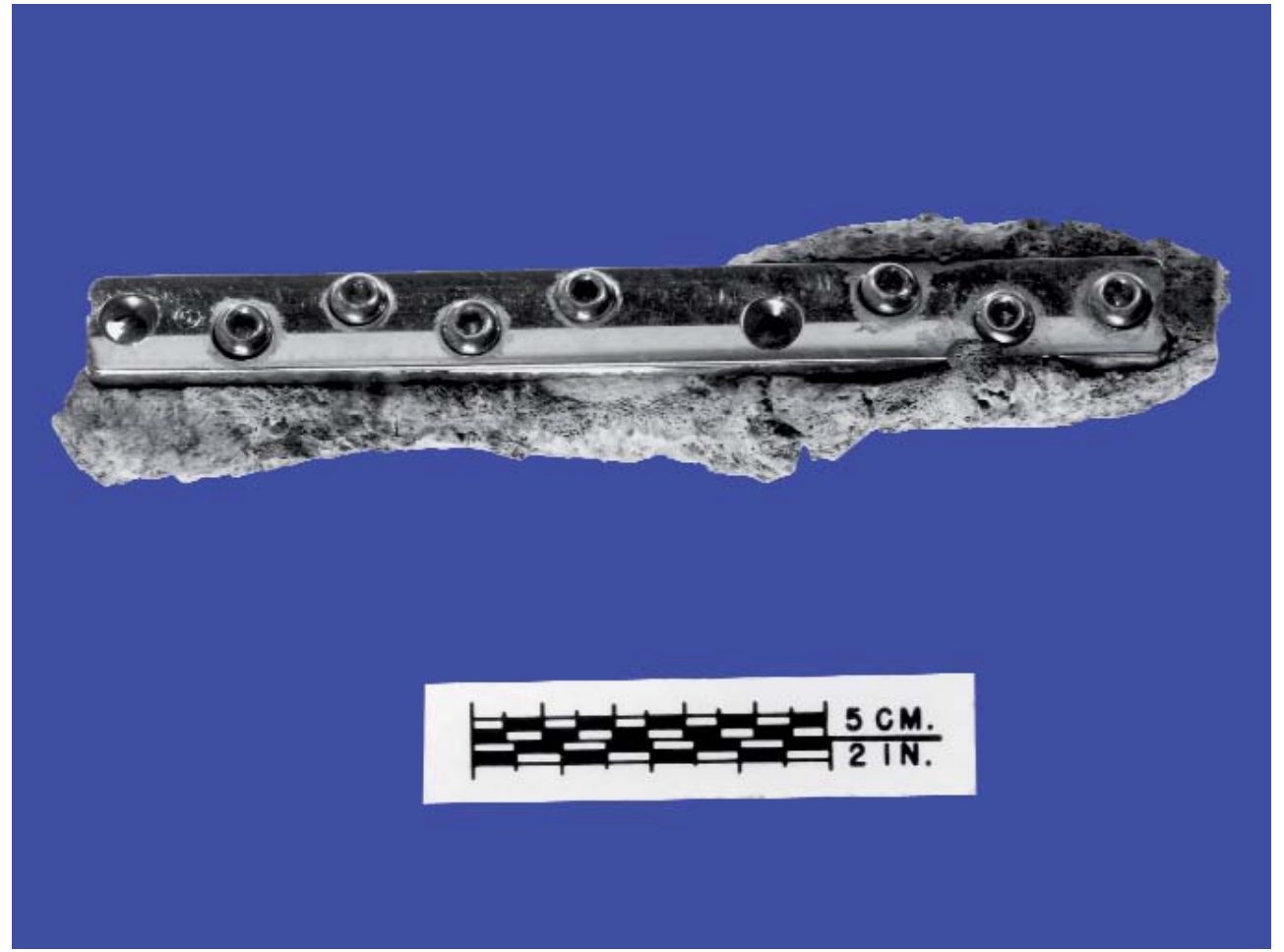

Figura 4.- Placa de osteosíntesis colocada antemortem en un animal (probablemente perro) remitida como caso forense. 